\title{
lodine Deficiency in Shendi Area in River Nile State, Northern Sudan
}

\author{
Faroug Bakheit Mohamed Ahmed ${ }^{1}$, Esam-eddin Bakheit Mohamed Ahmed ${ }^{2}$ \\ ${ }^{1}$ Departmentof Biochemistry, Faculty of Science and Technology, Shendi University, Shendi, Sudan \\ ${ }^{2}$ Departmentof ENT, Faculty of Medicine, Shendi University, Shendi, Sudan
}

\section{Email address:}

farougmhmd@gmail.com (F. B. M. Ahmed)

\section{To cite this article:}

Faroug Bakheit Mohamed Ahmed, Esam-eddin Bakheit Mohamed Ahmed. Iodine Deficiency in Shendi Area in River Nile State, Northern Sudan. European Journal of Preventive Medicine. Vol. 3, No. 6, 2015, pp. 193-196. doi: 10.11648/j.ejpm.20150306.16

\begin{abstract}
The study was conducted to assess iodine status of Shendi area inhabitants by determination of urinary iodine excretion of Shendi basic school children. Shendi area was divided into four geographical zones according to the difference in water sources.353pupils were included in the study. Most of cases (68.6\%) showed a urine iodine concentration between $10-30$ $\mu \mathrm{g} / \mathrm{dl}$ (normal). $7.9 \%$ of cases had urinary iodine excretion more than $30 \mu \mathrm{g} / \mathrm{dl}$ (above normal) and $23.5 \%$ of children were suffering from iodine deficiency; $16.4 \%$ of them had mild iodine deficiency, $4.5 \%$ of pupils showed moderate iodine deficiency and $2.6 \%$ had severe iodine deficiency according to WHO, 2001 standard. The high urinary iodine excretion was in the east of Shendi $(23.40 \pm 30.64 \mu \mathrm{g} / \mathrm{dl})$ and the low urinary iodine excretion was in the north of Shendi $(13.86 \pm 3.88 \mu \mathrm{g} / \mathrm{dl})$.Analysis of water samples from study zones showed some minerals which are goitrogenic such as fluoride and nitrate.
\end{abstract}

Keywords: Shendi Area, Iodine, Goitrogenic

\section{Introduction}

Iodine is very important for the proper functioning of the thyroid gland. The thyroid gland in the neck secretes a hormone called thyroxine, of which iodine is an important element (Walker, et al., 2007). Both insufficient and excessive iodine intake can result in thyroid disease. The term "iodine deficiency disorders" refers to the several consequences that iodine deficiency imposes on individuals. (Zimmermann, 2009). In areas where the daily iodine intake is $<50 \mu \mathrm{g}$, goitre is usually endemic (Vandam, 2001). A higher incidence of nodular goitre and less differentiated types of thyroid carcinoma have been observed in iodine deficient regions (Zonenberg, et al., 2007).

Iodine deficiency gives rise to hypothyroidism, symptoms of which are extreme fatigue, goitre, mental slowing, depression, weight gain, and low basal body temperatures (Felig and lawrence, 2001).Iodine deficiency disorders (IDD), which can start before birth, jeopardize children's mental health and often their very survival. Serious iodine deficiency during pregnancy can result in stillbirth, spontaneous abortion, and congenital abnormalities such as cretinism, a grave, irreversible form of mental retardation that affects people living in iodine-deficient areas of Africa and Asia (WHO, 2004).
Iodine deficiency is a significant public health problem (Andersson et al., 2005). According to $\mathrm{WHO}$, in 2007, nearly 2 billion individuals had insufficient iodine intake, a third being of school age. (WHO, 2008). In March 2006, iodine deficiency remained a serious public health problem in the developing world. Iodine deficiency is also a problem in certain areas of Europe. In Germany it has been estimated to cause a billion dollars in health care costs per year (Patrick, 2008). Lacking in iodine during human development causes a fall, in average, of 12 IQ points in China (Qian, et al, 2005). In developing countries, iodine deficiency has been identified as one of the modifiable factors that have an adverse effect on child development (Walker, et al., 2001)

Iodide is well absorbed from the intestine and is rapidly excreted by the kidney. The most sensitive method for evaluation of IDD control program is the determination of urinary iodine excretion (WHO, 2001). A 24-hour urine iodine collection is a useful medical test, as approximately $90 \%$ of ingested iodine is excreted in the urine.Iodine deficiency is treated by ingestion of iodine salts, such as found in food supplements. Mild cases may be treated by using iodized salt in daily food consumption, or drinking more milk, or eating egg, yolks and saltwater fish (Griffing, 2009).

The aim of this study is to determine of iodine deficiency 
inShendi area and detection of water supplements' role on iodine intake in study area.

\section{Materials and Methods}

\subsection{Subject}

Three hundred fifty threechildren ( $6-9$ years) from basic schoolchildren in Shendi area were selected randomly to determine the urinary iodine concentration.

\subsection{Sample Selection}

Random sampling technique was used. Shendi town was divided into four geographical zones: north, south, east, and west. From each zone two schools (boys\& girls) were selected. Samples were collected in the period from January to February 2009.

\subsection{Method}

1. Questionnaire: Include questions about sex, age, residence, source of water supply and iodized salt consumption among Shendi population.

2. Laboratory investigations: Sandell- kolthoff reaction was done to determine the urinary iodine excretion. Initially the urine is digested in strong acid at high temperature; thereafter the color change of ammonium sulfate with another substance (arsenic acid) is accelerated by iodine as catalyzing agent. The speed of the change in color depends on the iodine concentration. Comparing to standard solution with known iodine content was performed with colorimeter. This reaction, which is called the Sandell-Kolthoff reaction(WHO,2001), has been diagramed as follows:

$$
\begin{aligned}
& 2 \mathrm{Ce}^{+4}+2 \mathrm{I}^{-} \longrightarrow 2 \mathrm{Ce}^{+3}+\mathrm{I}_{2} \\
& \mathrm{I}_{2}+\mathrm{As}^{+3} \longrightarrow \mathrm{As}^{+5}+2 \mathrm{I}^{-}
\end{aligned}
$$

The Ceric ion has a yellow color, while the Cerous is colorless.

3. Colorimeter was used for estimation the urinary iodine concentration.

\subsection{Sampling}

To each urine sample a few drops of formalin were added and then kept refrigerated until were delivered to the laboratory after one week to determine the urinary iodine excretion.

\subsection{Statistical Analysis}

The data was analyzed by using Statistical Package for Social Sciences (SPSS), Windows version16, 2012. Percentage, mean and standard deviation, $\mathrm{P}$ value and correlation relation were calculated.

\section{Results}

The WHO, 2001 standards were utilized to demonstrate the whole sample iodine status. According to this criteria there was $2.6 \%$ of cases had severe iodine deficiency $(<2 \mu \mathrm{g} / \mathrm{dl})$. Moderate $(2-4.9 \mu \mathrm{g} / \mathrm{dl})$ and mild $(5-10 \mu \mathrm{g} / \mathrm{dl})$ iodine deficiency were found in $4.5 \%$ and $16.4 \%$ of the study sample respectively. There for $68.6 \%$ of the study sample was found to have urinary iodine concentration of $10-30 \mu \mathrm{g} / \mathrm{dl}$ which is normal and $7.9 \%$ had concentration more than $30 \mu \mathrm{g} / \mathrm{dl}$. Urinary iodine excretion in schoolchildren of the four geographical zones it is evident that most cases had a urine iodine concentration of $(10-30 \mu \mathrm{g} / \mathrm{dl})$ which is normal (Figure $1 \&$ Figure 2).

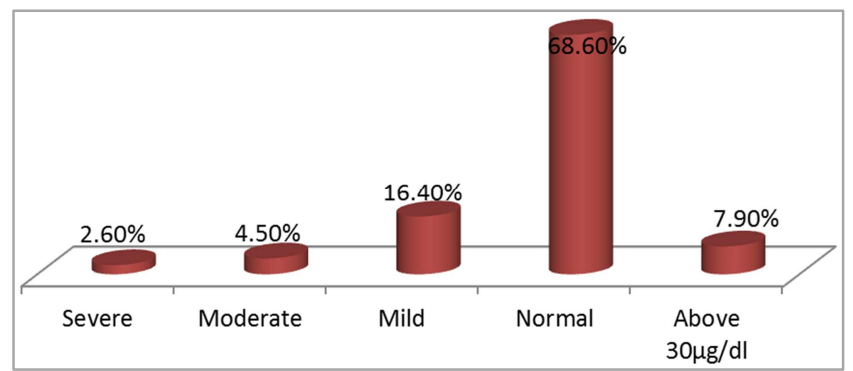

Figure 1. Urinary iodine concentration of study area according to WHO scales.

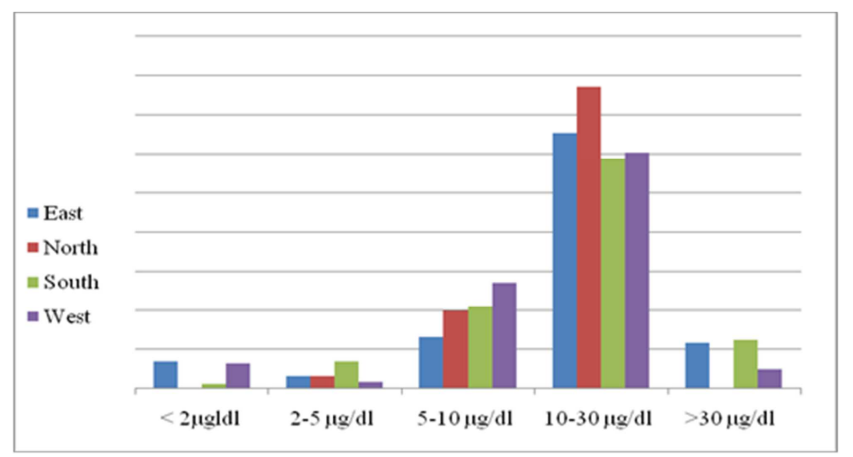

Figure 2. Urinary iodine concentration in schoolchildren according to zones.

The mean urinary iodine excretion of children in the four study zones it showed that the difference between four groups was statistically significant $(p<0.005)$. The mean of urinary iodine excretion according to sex it showed that females had higher values than males. The difference in mean urinary iodine excretion per sex was statistically significant $\mathrm{p}<0.01$ (Table $1 \&$ Table 2).

The urinary iodine concentration according to WHO scales between both sexes it is showed that $26.9 \%$ of females were suffering from iodine deficiency, $10.8 \%$ of them had severe iodine deficiency, $19.3 \%$ of them had moderate iodine deficiency and $69.9 \%$ of them had mild iodine deficiency. While $19.9 \%$ of males suffering from iodine deficiency, $8.8 \%$ of them had severe iodine deficiency, $20.6 \%$ of them had moderate iodine deficiency and $70.6 \%$ had mild iodine deficiency. Urinary iodine excretion was found to be reversely proportional to schoolchildren age in Shendi area. Schoolchildren at 9 years of age showed the lowest urinary iodine excretion $(13.62 \mu \mathrm{g} / \mathrm{dl})$ while those at 6 years of age showed the highest urinary iodine excretion $(22.61 \mu \mathrm{g} / \mathrm{dl})$. The difference per age in urinary iodine excretion was statistically 
significant $(\mathrm{p}<0.05)$ (Table 3\&Table 4).

Table 1. The mean and standard deviation of urinary iodine excretion ofthechildren in four study zones.

\begin{tabular}{llll}
\hline Zone & N & Mean & S.D. \\
\hline North & 96 & 13.86 & 3.88 \\
South & 74 & 17.43 & 11.93 \\
West & 85 & 14.46 & 11.23 \\
East & 98 & 23.40 & 30.64 \\
\hline
\end{tabular}

The concentration of some minerals and anions that affect the iodine metabolism in water samples from four study area (Table5).

Table 2. The mean and standard deviation of urinary iodine excretion according to gender.

\begin{tabular}{llll}
\hline Sex & N & Mean & S.D \\
\hline Males & 171 & 15.49 & 10.88 \\
Females & 182 & 21.16 & 26.45 \\
\hline
\end{tabular}

Table 3. The urinary iodine concentration according to WHO scales between both sexes.

\begin{tabular}{|c|c|c|c|c|c|}
\hline Sex & Severe $(<2 \mu \mathrm{g} / \mathrm{dl})$ & Moderate $(2-5 \mu \mathrm{g} / \mathrm{dl})$ & Mild (5 - $10 \mu \mathrm{g} / \mathrm{dl})$ & Normal $(10$ - $30 \mu \mathrm{g} / \mathrm{dl})$ & $>30 \mu \mathrm{g} / \mathrm{dl}($ Above 30) \\
\hline Male $(\%)$ & 1.8 & 4.1 & 14.1 & 74.1 & 5.8 \\
\hline Female $(\%)$ & 3.4 & 4.9 & 18.7 & 63.1 & 9.9 \\
\hline
\end{tabular}

Table 4. The mean and standard deviation reference with age.

\begin{tabular}{l|lll}
\hline Age & N & Mean & S.D. \\
\hline 6 years & 93 & 22.61 & 27.55 \\
7 years & 89 & 20.09 & 19.05 \\
8 years & 86 & 17.42 & 20.75 \\
9 years & 85 & 13.62 & 11.02 \\
\hline
\end{tabular}

Table 5. The concentration of some minerals and anions in water sources samples.

\begin{tabular}{|c|c|c|c|c|}
\hline $\begin{array}{ll}\text { Minerals } & \text { Region } \\
\end{array}$ & North & East & West & South \\
\hline Fluoride (mg/l) & 0.15 & 0.35 & 0.35 & 0.15 \\
\hline Nitrate (mg/l) & 3.0 & 3.0 & 3.0 & 3.0 \\
\hline $\mathrm{CaCO}_{3}(\mathrm{mg} / \mathrm{l})$ & 160 & 160 & 160 & 160 \\
\hline Calcium (mg/l) & 30 & 36 & 34 & 30 \\
\hline
\end{tabular}

\section{Discussion}

The selection of Shendi area to conduct this study was attributed to the medical observation that there were a lot of cases of goiter and thyroid disorders in Shendi hospitals. The area was divided into four zones; north, east, south and west from which samples were selected randomly for determination of urinary iodine concentration.

In this study, the grades of urinary iodine excretion depend on the WHO, 2001classification: $<2.0 \mu \mathrm{g} / \mathrm{dl}$ (severe); 2.0 $4.9 \mu \mathrm{g} / \mathrm{dl}$ (moderate); $5.0-10.0 \mu \mathrm{g} / \mathrm{dl}$ (mild) and $10.0-30$ $\mu \mathrm{g} / \mathrm{dl}$ (normal). The total mean of urinary excretion is $(18.42 \pm$ 20.62). The large standard deviation indicates the large difference in values of urinary iodine excretion in studied schoolchildren. The study revealed that the majority of highest levels (above $30 \mu \mathrm{g} / \mathrm{dl}$ ) of urinary iodine excretion were observed to be in southern and eastern regions. These observations could explain the highest mean values of urinary iodine excretion for schoolchildren from eastern $(23.4 \mu \mathrm{g} / \mathrm{dl})$ and southern $(17.4 \mu \mathrm{g} / \mathrm{dl})$ regions of Shendi area.

Four factors; foodstuffs, age, sex and area zone were clearly obtained from this study to affect the urinary iodine excretion. There was a highly significant difference between both sexes for urinary iodine excretion $(p<0.01)$. There was also significant difference between the four regions for urinary iodine excretion $(p<0.005)$. This significance in such a small geographical area (Shendi) may indicate the implication of other cofactor than iodine deficiency in this goitrogens. This is substantiated by higher rates of iodine excretion in eastern Shendi especially among some females schoolchildren (more than $100 \mu \mathrm{g} / \mathrm{dl}$ ), and this might be probably due to higher consumption of goitrogens, which may lead to appearance of symptoms of iodine deficiency (thyroid disorders).

In most cities, surface water is the main source of drinking water. Treatment and disinfection of this water are rather problematic, which contain high levels of minerals salts in contrast to the River Nile water. Drinking water of study areas contained some goitrogenic minerals; fluoride, nitrate, potassium, magnesium and calcium. Although were found in small concentration but were affective on long time, and were attributed to induce highurinary iodine excretion among schoolchildren of study sample. The erroneous usage of toothpaste especially during childhood may take place in the increment of fluoride effect the iodine metabolism and consequent may causes increase in highurinary iodine excretion among schoolchildren.

En masse, the most of iodine deficiency cases had mild urinary iodine excretion and there were some cases had urinary iodine excretion more than $30 \mu \mathrm{g} / \mathrm{dl}$ (above than normal). In brief, the iodine deficiency in Shendi area was at the mild deficiency degree and due to the effect of goitrogenic and dietary iodine deficiency. This hypothesis (goitrogenic effect) is supported by the observation that the most of Shendi population were eating foods containing iodine such as fish, eggs, yogurt, milk, onions, cheese, radishes and watercress at least weekly.

\section{Conclusion and Recommendation}

Most of schoolchildren (68.6\%) had normal urinary iodine excretion $23.5 \%$ were suffering from iodine deficiency and $7.9 \%$ had urinary iodine excretion more $30 \mu \mathrm{g} / \mathrm{dl}$. Some goitrogenic minerals and anions (such as $\mathrm{F}^{-}$and $\mathrm{NO}_{3}^{-}$) were concentrated in the water sources of study area. Attempts should be made to reduce the effect of goitrogenic minerals in water sources of study area. Identifying the 
goitrogenic-containing foodstuff and organizing their consumption.

\section{References}

[1] Andersson M., Takkouche B., Egli I., Allen H. and Benoist B. (2005).Current global iodine status and progress over the last decade towards the elimination of iodine deficiency. Bull. World Health Organ. 83 (7): 518-25. PMC, 2626287, PMID16175826.

[2] Felig P. and Lawrence A. (2001). Endemic goitre. Endocrinology \&metabolism. McGraw-Hill Professional. ISBN 978-0-07-02200-1.

[3] Griffing G. T. (2008). Iodine deficiency, Authors and editors: Stephanie L. Lee and. Updated: Apr 22, 2008.

[4] Patrick L. (2008). Iodine: deficiency and therapeutic considerations. Altern Med Rev 13 (2): 116. PMID 18590348.

[5] Qian M., Wang D., and Watkins W.E. (2005).The effects of iodine on intelligence in children: a meta-analysis of studies conducted in China. Asia Pacific Journal of Clinical Nutrition 14 (1): 32-42.

[6] Vandam J.P.M. (2001). The epidemiology of thyroid disease.
Oxford journal medicine. British Medical Bulletin. vol. 99(1),39-51.

[7] Walker S. P., Wachs T. D. and Gardner J. M.(2007). Child development: risk factors for adverse outcomes in developing countries. Lancet 2007; 369:145.

[8] World Health Organization. (2001) Assessment of iodine deficiency disorders and monitoring their elimination. A guide for programmers managers. Geneva: WHO, (WHO/NHD/01.1.).

[9] World Health Organization (2004).Micronutrient deficiencies, Iodine deficiency disorders. The WHO electronic Library of Evidence for Nutrition Actions.

[10] World Health Organization (2008).Iodine: deficiency and therapeutic considerations. Altern Med Rev 13 (2): 116. PMID 18590348.

[11] Zimmermann M.B. (2009). Iodine deficiency. Endocr. Rev,30:367

[12] Zonenberg A., Zarzycki W., Telejko B., Modzelewska A., Nikolajuk A., Rybaczuk M., Dzieciol J., Siewko K., Kinalska I \& Gorska M. (2007). The changes in the incidence of nodular goitre, thyroid cancer and urine excretion of iodine in the inhabitants of north eastern Poland in 1997 and 2005.Endocrine Abstracts, 14 P328. 